\title{
¿Muerte de Dios, muerte de hombre?
}

Martha Zechmeister,

Universidad de Passau,

Centro de Reflexión Teológica,

San Salvador.

En Europa se discuse "el fin del proyecro de la humanidad". Se considera que el ser humano, tal como lo conocemos, ha terminado en un estado de frustración y, por eso, se ha superado el antiguo presupuesto de que la esencia humana es intocable. Se anuncian métodos para optimizar genético-tecnológicamente la limitación de la esencia humana. Este hombre optimizado ofrece con frecuencia muchas semejanzas con el superhombre de Nietzsche, el hombre liberado de "toda compasión decadente ante los débiles y fracasados" para ensalzarse a si mismo como el "ser superior", lo cual siempre queda reservado a una pequeña élite. De esa manera se puede legitimar un mundo en el cual sólo unos pocos vivirán a costa de muchos. Este es el tema de este artículo, y en este contexto, quisiera retomar y dar fuerza al legado del monoteismo judeo-cristiano. Pero hay que recordar que al Dios bíblico sólo se lo puede reconocer allé donde el ser humano se vuelca hacia los pobres y débiles para ayudarlos a conseguir sus derechos.

Friedrich Nietzsche anunció con pathos profético la "muerte de Dios". En Europa, durante el último siglo, esta "muerte de Dios" parecía avanzar de forma incontenible. Los té́logos y teólogas tuvimos que enfrentar la realidad dolorosamente. Con los medios a nuestro alcance intentamos, con honradez, mantenemos firmes en medio de ella. Ahora, sin embargo, somos conscientes del drama de que allá donde muere Dios, también el ser humano está seriamente amenazado de muerte. Este es el contexto de estas reflexiones: la amenaza de la "muerte del hombre". Y de ahí también algo que debe tener en cuenta la teología: la —buena- Noticia que anunciamos puede sonar a muchos a anacronismo o ingenuidad. 
Tras los clásicos de la crílica de la religión, Feuerbach, Marx, Freud, a muchos pensadores, y desde hace ya mucho tiempo, les pareció que bastaba con deshacerse de la idea de Dios, aplastante y prepotente, para que el ser humano pudiera erguirse libre y plenamente. Por amor a la humanidad, a su dignidad y a su evolución integral, se hacía necesario destronar a Dios. Pero, en mi opinión, Nietzsche vio lo que estaba sucediendo con mayor agudeza que los "ateos por amor al hombre", aunque esto no quite nada de su irreconciliable oposición al cristianismo. En efecto, Nietzsche habla de las "sombras" que la muerte de Dios empieza a proyectar sobre Europa. La muerte de Dios arrastra consigo una catástrofe de dimensiones inimaginables. $Y$ tiene por ingenuos a quienes no inluyen que "las masas no se den cuenta de ella, ni puedan saber lo que se hundirá, por haber sido minada esa fe: todo lo que se apoya en ella y con ella se enlaza y de su savia vive, por ejemplo, toda la moral europea"'.

La misma intuición formula Michel Foucault en su Arqueología del saber': "Es muy posible que hayan matado a Dios bajo el peso de todo lo que han dicho, pero no piensen que lo que han dicho va a hacer que un hombre sobreviva más que $\mathrm{El} "$.

La pregunta, pues, sigue en pie y es muy disculida en la actualidad: " $¿ Q u e ́$ es el ser humano?". "¿Qué hace al hombre ser hombre?". Sea cual fuere nuestra postura ante el debate provocado por Sloterdijk, el tema está sobre el tapete y debe ser debatido. Y en lo personal, pienso que, en este contexto, los teólogos y las teólogas deberíamos sentimos culpables, si, al participar productivamente en el debate, no hiciéramos memoria del Dios cristiano.

Según Sloterdijk, el "proyecto humanidad", desde el que la tradición occidental se ha pensado a sí misma, ha fracasado definitivamente'. En efecto, todos los intentos de educación humanista han reducido a los seres humanos a animales domésticos, por una parte, y, por otra, no han podido impedir que se conviertan en bárbaros. Para Sloterdijk, el humanismo es, en definiliva, parte del problema de la violencia, aunque intente presentarse a sí mismo como su solución. Por eso aboga decididamente en favor de la destrucción de cualquier barrera ética, que dificulte las nuevas posibilidades que hoy ofrece la descodificación del genoma humano y los avances de la medicina genética. Hay que descarlar el "falso miedo de jugar a ser Dios", dado que, para que este ser humano de esencia limitada dé el salto que necesita, mucho le ayudaría el apoyo de medios genético-tecnológicos; en consecuencia, la moral debe estar a la altura de los

1. Fröhliche Wissenschafi (La gaya ciencia), Nr. 343.

2. M. Foucaul, Archäologie des Wissens (Arqueologia del saber), Frankfurt, 1973, p. 301.

3. P. Sloterdijk, Regeln für den Menschenpark - Ein Antwortschreiben zu Heideggers Brief über den Humanismus (Reglas para el "parque" de seres humanos. Una respuesla a la carta de Heidegger sobre el humanismo), Frankfurt a. M., 1999. 
avances del progreso tecnológico. Las vanguardias de la ciencia y las élites filosóficas deben hacer una alianza para tomar en sus manos, con decisión, la creación del "nuevo ser humano".

Esto significa poner fin, por ilusoria, a la afirmación de la igualdad en dignidad de lodos los seres humanos, y hacerlo con plena conciencia. Entonces, las "élites" —o quizás, dicho con mayor precisión, los autonombrados "hombres de poder"- se elevan sobre las mayorias, que se convierten en objeto de experimenlos de gran envergadura.

No quisiera dar demasiada importancia al diagnóstico de Sloterdijk. Sin embargo, por lo que se puede vislumbrar, sí creo que apunta a un proceso por el cual vamos a ser arrollados de manera incontenible, y frente al cual parece que nos encontramos sin esperanza, sin perspectiva y en retirada.

Es obvio, pienso yo, que en semejante escenario "muere" lanto el ser humano, tal como lo conocemos, como la idea de humanidad, que nos es familiar. Se acaba con la idea de que el hombre nunca puede convertirse en objelo del hombre. Pero esto plantea enlonces la pregunta de cómo salvar al hombre, en su identidad, como sujeto y con su hambre y sed de justicia, en favor de todo lo que tenga rostro humano. En forma concisa, quisiera resumir la tarea que a nosotros, teólogos y teólogas, impone esta situación: "Quien quiera resistir a esta perniciosa muerte del ser humano, sólo podrá hacerlo a partir de la fuerza de la memoria del Dios cristiano". Esta memoria eslá presente en la Biblia, en los textos de los místicos y, sobre todo, en los grandes textos de oraciones. En ellos, como profunda sabiduria de la humanidad, se ha concentrado lo que hace al hombre ser hombre. Como teólogos y leólogas tenemos que hacer uso de estos recursos y ponerlos a producir, con valentía, en "la batalla alrededor del hombre".

\section{¿Ha llegado el fin del monoteísmo?}

“¿Adiós al monoteísmo?”. Para muchos de nuestros conternporáneos, así parece mostrarlo el fracaso, una vez más, del proceso de paz entre israelíes y palestinos: el monoteísmo ha llegado a su fin. La lucha por el "monte santo", la destrucción mutua de los lugares santos, las oraciones que llaman a la venganza, todo ello no ha podido haber entrado con mayor virulencia, en la opinión pública mundial.

Donde, de forma determinante, las religiones monoteístas configuran todavía la conciencia de los seres humanos, parece imposible construir un Estado mo-

4. J. B. Metz, Wohin ist Gott, wohin denn der Mensch? (¿A dónde va Dios? ¿A dónde va el hombre?), en F.-X. Kaufmann/J. B. Melz, Zulanfisfähigkeir. Suchbewegungen im Christentum (La capacidad del futuro. Movimientos de búsqueda en el cristianismo), Freiburg, 1987, pp. 130-143. 
derno. Tampoco parece tener fin la espiral, mortal e irracional, del odio y la violencia allá donde diferentes grupos élnicos y religiosos, con sus reivindicaciones de poder y territorio, descargan su energía bélica, en nombre de la rivalidad por el monopolio de Dios. "Donde Dios y fe se mezclan con país y legitimidad, se llega antes al infierno que al cielo; $y$ en ese lugar no hay una mesa de negociación"s.

Al mundo le preocupa sobre todo que el confliclo no quede reducido a una región. El monoteísmo, con su pretensión de poder excluyente y fundante, no sólo parece poner en peligro la coexistencia racional de poblaciones de diferentes orígenes culturales, sino que puede convertirse en amenaza mundial. La bolsa, la instilución más sensible para deteclar los cambios que suceden en el mundo globalizado, reacciona, ciertamente, ante estos problemas. El Secretario General de Naciones Unidas, Kofi Annan, refiriéndose a la escalada de la violencia en Israel, dijo: "Todos los países están conslemados, los pobres y los ricos, pero muy especialmente los pobres"'t.

El conflicto actual, pues, refuerza la antigua sospecha de la crílica de la religión: el monoteísmo no sería más que la prolongación de los propios intereses. "Nadie mejor que Dios, como centinela de los grandes señores de la guena"'. Desde los caballeros de las cruzadas, que en la edad media se enfrentaron a los santos guerreros del Islam, pasando por los conquistadores que, al comienzo de la nueva era, en nombre de la fe cristiana, extinguieron las culturas indígenas de América Latina y, convencidos de la superioridad de la "cultura occidental cristiana", dirigieron la explotación económica de este continente por parte de los europeos, hasla el momento actual en que los fundamentalismos basados en religiones monoteístas se comportan con violencia frente a otras formas de creer y de pensar, en todos estos fenómenos, aparece la historia de religiones monoteístas, impulsada por la dinámica de la imposición imperialista de lo suyo propio.

Según un teórico de la cultura, por muy fascinantes que sean los progresos culturales logrados a lo largo de los siglos, a través de las diversas formas del monopolio de Dios, queda en pie, tanto más inexorablemente, el axioma: "en nuestro mundo multicultural no hay lugar para religiones que reivindiquen monopolios y estrategias de separación del otro's . La autoconciencia monoteísta se muestra como peligroso vestigio de tiempos arcaicos, como antílesis de la autoconciencia del mundo civilizado y democrático.

5. Josef Jofre, Heilloses Land (Ticra sin salvación), en Die Zeil Nr. 43, 19 de oclubrc, 2000 . p. 1.

6. Conferencia de prensa del 19 de octubre, de 2000.

7. E. Nordhofen, Die Zukunft des Monotheismus (EI fuluro del monoteísmo), en Merkur 53 (1999), p. 831.

8. H. Haarmann, Religion und Autoritäı. Der Weg des Gottes ohne Konkurrenz (Religión y autoridad. El camino de Dios sin compelencia), Hildesheim, 1998, p. 161. 


\section{Elogio del politeísmo}

En este conlexlo, parecería obvio que la única posibilidad racional y humana es adherirse al gran elogio del politeísmo, que en Europa recorre la historia del pensamiento de los dos últimos siglos". Friedrich Nielzsche dio el tono en La gaya ciencia, y en la actualidad lo siguen, con gran énfasis, pensadores excelentes como Richard Rorty y Gianni Vattimo"'. La tradición judeo-cristiana, y su legado profano en la historia europea, ha violentado a los seres humanos bajo cl diclado de una norma y de una verdad no perspeclivista. Sólo si nos decidimos a abandonarla podremos volver a recuperar la visión de los griegos, en la cual "un dios no era la negación o la difamación de otro dios". Y sólo bajo ese cielo se abrirá un espacio en el cual el individuo podrá respirar con libertad, y en el cual "se animará a la mayor diversidad posible, libre de conduclas violentas"". Sólo si nos decidimos a renunciar a toda reivindicación de unicidad y exclusividad será posible un sólido orden social, en una sociedad plural, así como un orden pacífico, en un mundo multicultural.

\section{El regreso desencantado de los dioses: liberación hacia la pluralidad}

Ha sido sobre todo Odo Marquard quien ha puesto de relieve estas ideas fundamentales, en su conocido arlículo de 1978, "Elogio del politeísmo"'2. En él no sólo desenmascaró el monoteísmo como peligroso y totalitario, sino también como anticuado, pues, con el advenimiento de la vida moderna, Dios se habría retirado y refugiado en el final de su propio mundo. Convertido en un "sin mundo", Dios se habría ido consumiendo lentamente hasta llegar a su propia

9. "Lo que necesitamos es el monoteismo de la razón y del corazón, y el politeísmo de la fuerza creadora y del arle", formulado ya en "Älsessen Systemprogram des Deutschen Idealismus" (El programa más antigun del sistema del idealismo alemán), 1796, por Hegel, Hölderlin y Schelling. Se busca un programa de unión entre razón y mitología. Véase M. Lutz-Bachmann, Der eine Gott und die vielen Götser. Monotheistischer Wahrheitsanspruch versus "postmoderner Toleranz" (El Dios único y los dioses múltiples. Reivindicación monoleista de la verdad versus "tolerancia postmoderna"), en: Gottesnamen. Gott im Bekenntnis der Christen (Nombres de Dios. Dios en el culto de los cristianos) publicado en M. Lutz Bachmann, Berlín, 1992, pp. 193-205.

10. R. Rorty, Ein Prophet der Vielfalt (Un profeta de pluralidad), en Zeit Nr. 35, agosto de 2000, p. 41; G. Vattimo, Die Mosken der Weisheit (Las mácaras de la sabiduría), en: Zeir Nr. 35, agosto de 2000, p. 41.

11. R. Rorty, Ein Prophet der Vielfalt, p. 41. Véase Fröhliche Wissenschaft, Nr. 143 "En el politeísmo se prefigura el escepticismo y la multiplicidad de espiritus del hombre: la energía para crear ojos nuevos y propios y siempre lo que es más nuevo y más propio".

12. O. Marquard, Lob des Polytheismus (Elogio del politeísmo), publicado en H. J. Höhn, Krise der Inmanenz. Religion an den Grenzen der Moderne (Crisis de lo inmanente. La religión en el límite de lo moderno), Frankfurt, 1996, pp. 154-173. 
muerte. Pero, a pesar de este desaparecimiento de Dios, la crítica de la tradición judeo-cristiana sigue siendo para Marquard el requisito indispensable de toda crítica, pues, aun con la desaparición de Dios, el monoteísmo sigue ejerciendo efectos peligrosos, en sus versiones profanas, tanto en la historia de la filosofía ilustrada, como en todas las utopias social-revolucionarias, que exigen cambios radicales.

El "no tendrás olro Dios más que a mî" vuelve a resonar en la violenta reducción de las muchas historias, en las cuales, de modo inevitable, nos vemos envueltos los seres humanos, a la única historia. Y justamente en ella aparece el "monomito" (Monomythos) del avance incontenible hacia la libertad, como descendiente direclo del monoteísmo. La obligación totalitaria hacia la identificación con una única historia asfixia de forma implacable los caminos multiindividuales y multiculturales hacia la humanidad -y hay que reconocer que, en esie diclamen y en esta crítica de Marquard, hay mucho de verdadero y de legítimo.

Frente al legado despótico del monoteísmo, Marquard aboga por "el regreso desencantado del politeísmo": en contraposición al mono-mito de la historia del progreso, ofrece los "mitos múltiples", la variedad de las historias de los dioses. El regreso de los muchos dioses y sus historias deberá ser, ciertamente, desencantado, pues bajo las condiciones de la modernidad, la variedad se manifiesta como la división de poderes, en lo político; la competencia de las fuerzas económicas, en el mercado; la disensión, en las teorías y en las visiones del mundo y de los valores. El ser humano no debe permitir que nada lo controle del todo. "Libérate, es decir, cuidate de que los poderes que te atacan se mantengan a raya el uno al otro", reza el credo de Marquard"3.

\section{"La ilustración vuelve a recaer en mitología"}

La adhesión a este credo parece, a primera vista, inevitable para quien intenta resistir a los irracionalismos y fundamentalismos políticos, es decir, para quien afirma y propicia una sociedad humana, bajo las condiciones de pluralidad y multiculturalidad. Sin embargo, a partir de un análisis más riguroso surgen serias dudas. El elogio del politeísmo, en efecto, aparece, en la actualidad, en dos versiones diferentes. Unos conjuran el regreso desencantado de los dioses para fomentar la pluralidad y fundar la democracia sobre la base de la ilustración. Este modo de pensar va desde Hans Blumenberg, pasando por Odo Marquard, hasta Rorty y Vattimo. Otros también aceptan esta forma de pensar, pero lo hacen con tonos inquientantes.

Marquard se remite de modo expreso a unas palabras de Max Weber del año 1919, en que dice: "los muchos y viejos dioses - y por eso en forma de poder impersonal- salen de sus tumbas, ansían ejercer la violencia sobre nuestras

13. O. Marquard, Lob des Polytheismus, p. 159. 
vidas y comienzan de nuevo sus eternas luchas entre ellos"'4. ¿ ${ }^{\text {No bastan estas }}$ palabras para vislumbrar la peligrosa ambivalencia del discurso del regreso de los dioses y sus mitos? Max Weber habla desde el terror conjurado por la primera guerra mundial. El calastrófico desenlace sólo lo pudo presentir, en aquel entonces, como sismográficamente. Pero hoy, en presencia de la historia real de nuestro siglo $-\mathrm{y}$ sin abandonar el terreno de la ilustración-, ¿no será ingenuidad o ceguera pensar que basta la intención democrática para poder retomar sin peligro la idea del retomo de los dioses?

Esta idea y la proclamación de un nuevo paganismo permea el fascismo y el neofascismo del siglo XX. Ha sido Jacob Taubes, judío y filósofo de la religión, quien to ha recalcado y analizado con precisión's, en debate con Marquard. Comentando la tesis de Horkheimer y de Adorno, "La ilustración reincide en la mitología", en la introducción a la "Dialéclica de la ilustración" de 1944, dice lo siguiente. "'La ilustración reincide en la mitología" brilla como memento en las paredes de nuestra conciencia, en señal de la marcha triunfal del fascismo de la época, que destruyó los fundamentos morales y políticos de la vieja Europa. Este memento se ha transformado, sin duda, en el Biedermeier (romanticismo burgués) de nuestra posthistoria, en el sobrio protocolo del espíritu de nuestra época, en el que ocurren muchas cosas, pero no pasa nada. Los horrores de la primera milad del siglo XX han perdido su poder para los círculos liberales pluralistas"'th. A] interpretar la nueva llegada de los dioses y de los mitos como proceso humanizador, Taubes sólo lo puede considerar como "una versión ingenua de la dialéctica de la ilustración" - por no hablar de desprecio hacia ella.

A esta objección de Taubes podría, quizás, responderse que el contexto de sus afirmaciones ha cambiado dramáticamente, desde 1944, y que desde hace mucho tiempo el temor al terrorismo proviene de otros lugares. Pero esto no es respuesta, pues la nueva derecha (neofascismo) celebra ahora la idea de un retomo al paganismo y a sus dioses y milos. Después de haber sufrido durante más de mil años la imposición de la tradición judeo-cristiana, habría llegado la hora de volver a la genuina religión de Europa. Y difícilmente se le podrá absolver a Nieztsche de la sospecha de haber apadrinado tales ideas, cuando dice en El Anticristo: "El hecho de que las vigorosas razas del norte de Europa no hayan repudiado al dios crisliano, ciertamente, no habla en favor de su don religioso, para no decir nada de su gusto. ¡En casi dos milenios ni un solo nuevo dios! ¡Impera todavía... este lamentable dios del monótono teísmo cristiano! ¡Este ser híbrido hecho de cero, concepto y contradicción, en el cual están sancionados todos los instintos de décadence, todas las cobardías y cansancios del alma!"'?.

14. M. Weber, Wissenschaft als Beruf (La ciencia como profesión), Munich, 1919.

15. J. Taubes, Zur Konjunktur des Polytheismus (Sobre la conyuntura del politcísmo), Munich, 1996, pp. 340-351.

16. Ibid., p. 341.

17. F. Nietzsche, Antichrist, N. 19. 
Es evidente que la liberación de la imposición judeo-cristiana, en los representantes de la nueva derecha, no apunta hacia el espíritu de la democacia. Por el contrario, va unida a un enérgico rechazo de los principios de la ilustración sobre la igualdad de derechos y dignidad de todos los seres humanos - lo cual no ocurre sin menosprecio del ser humano.

Durante décadas quizás fue posible vivir, de una forma errónea, con la falsa seguridad de que tales ideas sólo serían defendidas por algunos círculos relrógados secretos. Pero hoy ya no, pues la xenofobia y el antisemitismo, inspirados en dichas ideas, van en aumento no sólo en actos espontáneos de violencia, sino que configuran un fenómeno social, que amenaza con convertirse en un peligro masivo; y no en algún que otro lejano país sin tradición democrálica, sino en la mismísima democracia europea. Las instituciones del Estado de derecho están hoy en día obligadas a enfrentar de forma explícita esta situación, aunque, con frecuencia, aparezcan llamativamenle impolentes y sin saber qué hacer ante esa tarea.

\section{Cara a cara con Nietzsche}

No se puede identificar sin más el anti-igualitarismo de Nietzsche y el desprecio fascista a la idea de igualdad en dignidad y derechos de todos los seres humanos. No se puede, pues, identificar sin más a Nietzsche con Hitler. Pero sigue en pie la inquielante pregunta de si no será caer en ingenuidad, o al menos trivializar las cosas, elevar a profeta de la civilización democrática al Nietzsche detractor de la democracia'".

Richard Rorty admite sin rodeos que invocar a Niezsche para estos fines sólo es posible si se le interpreta contra él mismo, contra su "polémica snob y poco perspicaz en contra de la democracia". Vatlimo, por su parte, no interpreta en absoluto el superhombre de Nietzsche como el ser humano que ha llegado a ser capaz de democracia. Lo que propicia es, más bien, que "la meta de la plenificación moral es 'un plural', un sujeto plural, que no está asentado sobre fundamento alguno seguro e inconmovible... El yo es un centro que recibe con hospitalidad, abierto a escuchar muchas voces, un arco iris variable de símbolos y referentes" - lo cual es, en último término, una "alegoría del amor al prójimo". Hasta aquí Vatlimo". Y ahora surge la pregunta, ¿se puede afirmar con seriedad que todo lo que en la obra de Nietzsche contradice lo que acabamos de exponer sería solamente una máscara o un resentimiento superficial, que no afectaría, en absoluto, a lo sustancial de este pensador?

18. E. Tugendhat, Der Wille zur Mach. Macht und Anti-Egalitorismus bei Nietzsche und Hitler - Einspruch gegen den Versuch einer Verharmlosung (La voluntad de poder. Poder y anti-igualitarismo, en Nictzsche y Hitler. Protesta contra el intento de una minimización), cn Die Zeit, Nr. 38, pp. $51 \mathrm{~s}$.

19. G. Vallimo, Die Masken der Weisheit, p. $41 \mathrm{~s}$. 
La tesis que queremos exponer a continuación es que, en el contexto actual, el núcleo del monoteísmo bíblico sólo se puede arlicular en un profundo y peligroso cara a cara con Nietzsche. Esta tesis se basa en la sospecha de que Nietzsche - aunque bajo la figura de escarnio y cinismo- ha comprendido el monoteísmo judeo-cristiano mejor que los que hoy rechazan dicho monoteísmo en nombre de la pluralidad y de la democracia.

En un texto central de La gaya ciencia, Nielzsche describe qué es el monoteísmo, es decir, la fe "en un Dios normal, junto al que no puede haber otros dioses más que falsos y mentidos" como "rígida consecuencia de la doctrina del hombre normal"2". Y en sus obras póstumas de 1885-1886, escribe que "el cristianismo, como ideal plebeyo, ha ido dañando, con su moral, al tipo de hombre fuerte, más desarrollado, y ha favorecido a un tipo de hombre-rebaño. Esto es una preparación al pensamiento democrático".

Según Nietzsche, la finalidad de abandonar el monoteísmo no es la de favorecer la democracia, sino todo lo contrario: desprecia el monoteísmo, porque, de acuerdo a su diagnóstico, es el inspirador determinante de los ideales democrático-igualitarios de la ilustración. En muchos lugares de su obra, manifiesta este desprecio. En la Genealogía de la moral, por ejemplo, "el surgimiento de la democracia, los tribunales de paz en lugar de la guerra, la legitimación de la igualdad de las mujeres y la religión de la compasión son 'síntomas de vida decadente"'21. Cristianismo y democracia serían, ambos, lo que hasta ahora ha anquilosado más profundamente a la humanidad ${ }^{22}$.

Para Nietzsche, la esclavitud es el postulado de todas las grandes culturas, y el "pathos de la distancia" frente a los débiles es la virtud de la clase distinguida y aristócrata. Por eso se queja de que con el monoteísmo se han elevado y nivelado las clases. "Lo esencial en una aristocracia buena y sana es... que acepta con buena conciencia el sacrificio de un sinnúmero de seres humanos, los cuales, por su bien, deben ser rebajados y reducidos a seres defectuosos, a esclavos, a instrumentos"2?.

Ante estas monstruosidades, que Nietzsche formula tan abiertamente, se hace inevitable la pregunta de si con ello no se desenmascara también la tesis politeísta en su versión benévola y democrática, y aparece como tesis aparente y superficial, en el mejor de los casos, como romántica transfiguración de la realidad.

El regreso de los dioses y sus mitos, ¿significa la realidad, la variada y atrayente diversidad, en la cual el individuo puede encontrar con libertad su propia felicidad, mediante el libre desarrollo de las fuerzas sociales $\longrightarrow$ no

20. Fröhliche Wissenschaft, Nr. 143.

21. F. Nietzsche, Kritische Studienausgabe (KSA) Bd. 5, p. 403.

22. Ibid., Bd. 9, p. 3.

23. Genealogie der Moral (Genealogía de la moral), Nr. 258s, KSA Bd. 5, p. 206. 
significará más bien la violenta lucha de los dioses? ¿No ensalza el tipo de ser humano, liberado de la compasión decadente ante los débiles y fracasados, para elevarse así él mismo a "una tarea más excelsa", a "ser más excelso", lo cual sólo está reservado a una pequeña élite? ¿Es el "politeísmo desencantado", la metáfora adecuada para el reconocimiento de la innegable pluralidad de las sociedades modernas y de la separación de lo poderes políticos, sólo sobre cuya base es posible la convivencia en un Estado de derecho ¿O no se enmascarará peligrosamente con esta metáfora —que sugiere una amena diversidad- una realidad muy conflictiva y cruel?

¿No se está jugando, por ejemplo, con la palabra global village ("aldea global"), cuando con ella se quiere ofrecer un modelo de convivencia amistosa y familiar de la única familia de los seres humanos? Para quien ve con realismo la humanidad del siglo XXI, ia qué se parece, sino a una lucha cruel por la supervivencia, de la cual sólo están exentos unos pocos privilegiados?

Desde esta realidad hay que preguntarse si la tesis politeista hace que desaparezcan las relaciones de opresión reinantes, y si no se la está rodeando de una manera espúrea de un halo mítico-divino. Y si miramos en profundidad a la realidad, ino es evidente que, tras la euforia de los mitos se esconde un monomito, que no puede ser más brutal y despótico, es decir, el mono-mito de las falacias del mercado? Si observamos con un mínimo de realismo el desarrollo de la economía mundial -incluso el desarrollo económico, en los paises del primer mundo-, ino vienen fatalmente a la memoria aquellas palabras de Nietzsche: "Hay que pensar en profundidad y defendernos de toda debilidad sentimental: la vida es esencialmente apropiación, herir y avasallar lo extraño y lo débil, opresión, dureza, coacción de formas propias, asimilación y, por lo menos, explotación... "??-1.

Frente a lo que domina nuestra realidad actual y a lo que dicta su legislación, el júbilo de los mitos politeístas no es más que la decoración ornamental del sistema. Por eso, los mitos sólo pueden conseguir, en realidad lo que también formula Marquard: hacer que la cruel realidad nos sea, hasta cierto punto, más agradable.

\section{Sobre lo central del monoteísmo judeo-cristiano}

En este contexto, surge con mayor fuerza la pregunta por lo central del monoteísmo judeo-cristiano. Siguiendo a Enmanuel Levinas, expondremos a continuación algunas breves tesis. Lo hacemos con la conciencia de que hay que tener también presente la terrible historia de la traición del monoteísmo a sí mismo, de sus perversiones y abusos.

24. Ibid., Nr. 258s, KSA Bd. 5, p. 207. 
1. "Yo soy Yavé, tu Dios, que te ha sacado de Egipto, de la casa de la esclavitud. No tendrás otro Dios más que a mí" (Ex 20,2s; Dt 5, 6s). "Yo soy Yavé y no hay otro salvador" (Is 43, 11).

Esta es la esencia del monoleísmo: la confesión del único Dios va unida a la liberación de todas las fuerzas y poderes que dominan al ser humano, abierta y despóticamente o sorda e inconscientemente. La declaración más profunda del monoteísmo bíblico dice, pues: nada deberá dominar y esclavizar al ser humano. Es, en sí mismo, la relativización de todas las falsas reivindicaciones absolutistas.

2. Desde aquí hay que comprender la "desmitologización", en su sentido más específico y cualificado, desde la propia pespectiva biblica. No significa esto negar las muchas historias en las que, de modo inevitable, se ven envueltos los seres humanos. Precisamente, la fe en el Dios judeo-cristiano no se puede articular sino en la fragilidad de las muchas historias. $Y$ el canon biblico es el paradigma. No es un "mono-mito". El misterio divino brilla más bien en la contradicción y en la tensión entre tradiciones muy diversas, que deben ser tenidas en cuenta, cada una de ellas, según su estatuto propio.

De lo que se trata en la desmitologización es, algo específico y cualificado: la des-divinización, el des-encantamiento. En palabras de Levinas: "el judaísmo, tomado en su conjunto, quizás no quería... olra cosa que el fin de las mitologías, de la violencia que ejercen sobre la razón"2s; rechaza "el poder espiritual de todas las relaciones que nazcan de la magia y de la violencia"

“Desmitologización" significa que los idolos son desenmascarados tal y como son: instrumentos al servicio de intereses concretos. Estos ídolos están en lucha. Hay que rechazar la legitimación mítico-divina del orden establecido, y así puede ser criticado y transformado. La ficción de que nuestro mundo es el "mejor de los mundos" es sólo una mentira que favorece a los que no tienen ningún interés en cambiarlo.

3. Prosigue Levinas: “El monoteísmo no es ninguna aritmética de lo divino. Hay que verlo, quizás, más bien como un don sobrenatural, como la capacidad de reconocer al ser humano como absolulamenle igual a otro ser humano, aun con las diferencias de tradiciones propias y mantenidas por cada uno"27. Es una escuela de acercamiento al extraño, al otro, y también es escuela de antirracismo. No hay ningún culto a "lo único", sin reconocer "al otro", al prójimo. Eslos olros no son meramente una nueva reproducción del yo, de modo que los conozco como otros sólo cuando empiezo a percibir el misterio de su alteridad. Y con frecuencia son escandalosamente extraños, otros.

25. E. Levinas, Schwierige Freiheit (La dificil libertad), Frankfurt ,1992, p. 105.

26. Ibid., p. 16.

27. Ibid., p. 126. 
Dicho de otro modo: la mistica divina cristiana es, en verdad, una mística del rostro del otro. Quien desea unificar las energías del corazón para buscar y palpar el rostro del Otro divino, deberá estar abierto y ser vulnerable ante el prójimo. Por eso, la mística cristiana conoce el dolor de la diferencia y de la ausencia. Por eso, también, nadie puede osar tratar a Dios de "tú" en la oración y, al mismo tiempo, degradar al otro a objeto de sus propios intereses. Si lo hace, es idolatría.

4. "Hacer justicia al débil y al pobre, ¿no es eso conocerme? Así habla Dios, el Señor" (Jer 22, 16). El reconocimiento de Dios como el salvador, el Dios que saca de la esclavitud, se consuma en el aclo de liberar a los que son víctimas de los poderes y las fuerzas dominantes. Quienes confiesan a un Dios único, rechazan ofrecer sacrificios humanos a los ídolos, lambién a los ídolos de la economía del mercado neoliberal. En palabras de Levinas: "La relación con los seres humanos en la que acaece el contacto con lo divino, no es una especie de 'amistad espirilual', sino aquella que se manifiesta, se ensaya y se cumple en una economía justa de la que todo ser humano es totalmente responsable"2*.

5. Con esto llegamos al último punto. Para aspirar a la igualdad entre todos los seres humanos hay que reconocer, antes que nada, un desequilibrio fundamental: la desigualdad que Levinas llama la "asimetría entre yo y los otros que sufren". Para la ética bíblica es fundamental el reconocimiento de que yo no soy igual a los otros, y en un sentido muy estricto: estoy obligado ante el otro, tengo una responsabilidad de la cual nadie me puede eximir, y, en consecuencia, me impongo a mí mismo exigencias más hondas que a los demás.

La confesión de la igualdad de derechos y de dignidad de lodos los seres humanos es un bien conseguido por la ilusiración europea con el cual no se puede jugar. La historia de la sociedad burguesa, sin embargo, mostró muy rápidamente que esta idea ha perdido su capacidad originaria y crítica para combatir las diferencias que hoy existen. De pronto, esa misma idea sirvió para encubrir las diferencias reales que siguen exisliendo. Por eso, en mi opinión, necesita estar fundamentada en la élica biblica, en la cual la concreta necesidad del prójimo se convierte en lugar decisivo del encuentro con Dios: lo que está en juego es, a la vez, la divinidad de Dios y la humanidad del hombre.

\section{Referencias bibliográficas}

J. Assmann, Moses der Ägypter. Entzifferung einer Gedöchınisspur (Moisés el egipcio. Descodificación de la memoria), München, 1998.

R. Faber, Politische Religion - Religiöse Politik (Religión política - Politica religiosa), Würzburg, 1997.

28. Ibid., p. 32. 
H. Haarmann, Religion und Autorität. Der Weg des Goltes ohne Konkurrenz (Rcligión y autoridad. El camino de Dios sin competencia), Hildeshcim 1998.

A. Halbmayr, Lob der Vielheit. Zur Kritik Odo Marquard am Monotheismus (Elogio dc la pluralidad. Sobre la critica al monoteísmo), Innsbruck. 2000.

E. Levinas, Schwierige Freiheit. Versuch üher das Judentum (La dificil libertad. Ensayo sobre el judaísmo), Frankfurt, 1992.

O. Marquard, "Lob des Polythcismus" (Elogio al politcismo), en Abschied vom Prinzipien (Adiós a los principios), Stuttgarl, 1981.

$O$, Marquard, "Einheit und Vielheit, en: Einheit und Vielheit. XIV Deurscher Kongref für Philosophic (Unidad y pluralidad. Congreso alemán de filosofia), Hamburgo, 1990, pp.1-10.

J. B. Metz, Theologie versus Polymythic oder Kleine Apologie des biblischen Monotheirmus (Tcología contra polimitía - o pequeña apologia del monolcísmo biblico), en 0 . Marquard, Einheit und Vielheit, Hamburgo, 1990, pp. 170-186.

J. B. Metz, "Monotheismus und Demokratic. Über Religion und Politik auf dem Boden der Moderne" (Monoteismo y democracia. Sobre religión y política sobre el Cundamento de la época moderna), en Jahrbuch für Politische Theologie, Bd.l (1996), pp. 39-52.

W. J. Mommsen, "Rationalisierung und Mythos bei Max Weber" (Razonalización y milo en Max Weber), en K. H. Bohrer, Mythos und Moderne. Begriff und Bild einer Rekonsiruktion (Mito y ćpoca moderna. Conccplo c imagen de una rceonstrucción), Frankfurl, 1983, pp. 382-402.

E. Nordhofen, "Die Zukunft des Monotheismus" (El futuro del monoteismo), en Merkur 53 (1999), pp. 828-846.

R. Rorly, "Ein Prophel der Vielfalt” (Un profela de la pluralidad), en Die Zeit, Nr. 35. agosto de 2000, p. 41.

J. Reikerstorfer, "Der Goll der Chrisıen und dic Fragmentierung der posimodernen Weli" (El Dios de los cristianos y la fragmentación del mundo postmoderno), en Concilium 3.3 (1997), pp. 304-310.

Th. Ruster, Der verwechselbare Goll. Theologie nach der Entflechtung von Christentum und Religion (El Dios confundible. Teologia después de la separación de cristianismo y religión), Frejburg, 2000.

L. Schwienhorst-Schönberger, "Gottesbilder des Alten Testaments" (Imágenes de Dios cn cl Antiguo Testamento), cn Theologisch Prakische Quarıalschrift 148 (2000), pp. 358-368.

F. Stolz, Einführung in den biblischen Monotheismus (Introducción al monoleísmo biblico). Darmstadt, 1996.

J. Taubes, "Zur Konjunktur des Polylheismus" (Sobre la conyunlura del politeísmo), en Vom Kuls zur Kultur (Del culto a la cultura), München, 1996.

E. Tugendhaft, "Der Wille zur Macht. Machl und Anti-Egalitarismus bei Nictzsche und Hitler - Einspruch gegen den Versuch cincr Verharmlosung" (La volutad de poder. Poder y anti-egalitarismo en Nietzsche y Hitler. Alaque al intenlo de una minimización), en Die Zeit, Nr. 38, pp. 51s.

G. Vattimo, "Die Masken der Weisheit" (Las máscaras de la sabiduría), en Die Zeit, Nr. 35 , agosto de 2000 , pp. $41 \mathrm{~s}$.

Maric-Theres Wacker y Erich Zenger, Der eine Goll und die Göttin. Gollesvorstellungen des biblischen Israel im Horizont feministischer Theologie (EI Dios único y la diosa. Representaciones de Dios en el lsrael bỉblico en el horizonte de la teología feminisla), Frciburg, 1991. 